\title{
La calle, el café y el prostíbulo. Espacios de sociabilidad en la obra de Pedro Herreros (1890-1937), un poeta español emigrante en Buenos Aires*
}

\begin{abstract}
Alfonso Rubio Hernández
Profesor del Departamento de Historia de la Universidad del Valle (Colombia). Correo electrónico: alfonso. rubio@correounivalle.edu.co. El autor es Filólogo de la Universidad de Zaragoza (España), magíster y doctor en Sistema de información y Documentación de la Universidad de Zaragoza (España). Miembro del Grupo de investigación Nación-Cultura-Memoria de la Universidad del Valle (Colombia). Entre sus publicaciones recientes tenemos: "Luis Carlos López: un poeta que mira a su alrededor" en Acta Literaria No. 51 (2015) y "Las librerías de la Compañía de Jesús en Nueva Granada: un análisis descriptivo a través de sus inventarios" en Información, cultura y sociedad No. 31 (2014). Entre sus temas de interés están historia social de la cultura escrita e historia archivística.
\end{abstract}

Recibido: 29 de junio de 2014

Aprobado: 21 de septiembre de 2015

Modificado: 26 de septiembre de 2015

Artículo de investigación científica

DOI: http://dx.doi.org/10.15648/hc.28.2016.4

Este artículo forma parte del proyecto: "Pedro Herreros (1890-1937): poeta del sencillismo. Estudio y recopilación de su obra completa", financiado por la Universidad del Valle (Colombia). Esta publicación está bajo una licencia Creative Commons Reconocimiento-NoComercial 4.0 
La calle, el café y el prostíbulo. Espacios de sociabilidad en la obra de Pedro Herreros (1890-1937), un poeta español emigrante en Buenos Aires

\title{
Resumen
}

A principios del siglo XX, la escena artística de Buenos Aires propulsó la creación de una esfera pública de debate y de crítica y configuró un espacio que articulaba la iniciativa privada e institucional con la sociabilidad del mundo artístico en lugares como plazas, parques o bibliotecas, y en establecimientos como cafés, clubes, librerías o sociedades literarias. Las marcas autobiográficas que recorren la obra poética de Pedro Herreros y su mirada de desprotegido emigrante nos sirven aquí para describir el contexto político-social de la época, en el que espacios como la calle, el café y el prostibulo propiciaron la expansión de nuevas formas de sociabilidad.

Palabras clave: lugares de sociabilidad, Buenos Aires, siglo XX, poesía, Pedro Herreros.

The street, coffee and brothel. Spaces of sociability in the work of Pedro Herreros (1890-1937), an immigrant spanish poet in Buenos Aires

\begin{abstract}
In the early twentieth century, the art scene in Buenos Aires encouraged the creation of a debate and criticism public sphere and set up a space that articulates private and institutional initiative with the sociability of the art world in places such as squares, parks or libraries, cafes, clubs, bookstores or literary societies. Autobiographical traits that spread throughout Pedro Herreros' poetry and his unprotected emigrant gaze serve here to describe the political and social context of the time, in which spaces like the street, cafés and brothels led to the expansion of new forms sociability.
\end{abstract}

Key words: places of sociability, Buenos Aires, twentieth century, poetry, Pedro Herreros.

\section{A rua, o café e o bordel. Espaços da sociabilidade na obra de Pedro Herreros (1890-1937), Um poeta espanhol imigrante em Buenos Aires}

\section{Resumo}

78 A princípios do século XX, o cenário artístico de Buenos Aires propulsou a criação de uma esfera pública de debate e crítica, e configurou um espaço que articulava a iniciativa particular e institucional com a sociabilidade do mundo artístico em lugares 
como praças, parques ou bibliotecas, e em estabelecimentos tais como cafés, clubes, livrarias ou sociedades literárias. As marcas autobiográficas que recorrem a obra poética de Pedro Herreros e o seu olhar de imigrante desprotegido aqui servem para descrever o contexto político-social da época, no qual os espaços como a rua, o café e o bordel propiciaram a expansão de novas formas de sociabilidade.

Palavras chave: lugares de sociabilidade, Buenos Aires, século XX, poesia, Pedro Herreros.

\section{La rue, le café et le bordel. Espaces de sociabilité dans l'œuvre de Pedro Herreros (1890-1937), un poète espagnol émigrant à Buenos Aires}

\section{Résumé}

Aux débuts du $\mathrm{XX}^{\mathrm{e}}$ siècle, la scène artistique de Buenos Aires a favorisé la création d'une sphère publique de débat et de critique et a configuré un espace qui articulait l'initiative privée et institutionnelle avec la sociabilité du monde artistique dans des lieux tels que des places, des parcs ou des bibliothèques, et dans des établissements tels que des cafés, des clubs, des librairies ou des sociétés littéraires. Les marques autobiographiques qui parcourent l'œuvre poétique de Pedro Herreros, et son regard d'émigrant démuni nous servent ici à décrire le contexte politique-social de l'époque où les espaces comme la rue, le café et le bordel ont facilité l'expansion de nouvelles formes de sociabilité.

Mots clés: lieux de sociabilité, Buenos Aires, $\mathrm{XX}^{\mathrm{e}}$ siècle, poésie, Pedro Herreros.

\section{Despierta la ciudad. Y en un momento}

hormiguea la vida en sus entrañas.

[...]

Yo, a esta hora febril, ando vagando

por las tipicas calles suburbanas.

\section{La Busca}

El café es el único palacio ideal de los soñadores de gaveta escasa. Cafetín que eres mi hogar y mi casa... iquiera Dios no seas también mi hospital!

Temor 
- ¿Allons? - dice la verde mujer de carne de opio.

$Y$ me lleva a sonar las trompas de Falopio.

Los arrojados del paraíso

Pedro Herreros

\section{INTRODUCCIÓN}

Para abordar la relación entre los hábitos sociales empleados por Pedro Herreros en su cotidianidad, descritos en su obra poética, y el contexto histórico bonaerense de las tres primeras décadas del siglo XX en que vivió, Lewis A. Coser y Jürgen Habermas nos proporcionan dos útiles puntos de partida. El café como lugar libre de reunión que se apoya en el ingenio y la inteligencia y no en consideraciones de privilegios sociales o morales, representa, como nos dijo Coser, una categoría de índice democratizador y una forma de integración, de intercambio y compensación de ideas, de comunicación y producción oral y escrita, de observación de tipos humanos ${ }^{1}$. Los principios sociales de la profesionalización del escritor, así como el ascenso de la producción y consumo de lo escrito a través de "formas de sociabilidad" que van evolucionando sus concepciones burguesas y su público culturalmente racionante hacia una cultura de masas, ampliamente publicitada por kioscos callejeros, librerías y prensa, donde se vio envuelta, sea nuestro caso, la capital argentina a partir de los comienzos del siglo XX, fueron expuestos por Habermas ${ }^{2}$.

Para el historiador francés Maurice Agulhon, la noción de "sociabilidad", designa un sistema de relaciones entre individuos o una aptitud de ellos para constituir y consolidar grupos humanos. Entre los investigadores latinoamericanistas, la sociabilidad es ampliamente tratada en la historia política y, desde que irrumpiera en el campo histórico a mediados de la

801 Lewis A. Coser, Hombres de ideas. El punto de vista de un sociólogo (México DF: Fondo de Cultura Económica, 1968), 35-41.

2 Jürgen Habermas, Historia y crítica de la opinión pública (México DF: Gustavo Gili, 1994 [1962]), 172-208. 
década de 1960 de manos de Agulhon, el concepto ha evolucionado hacia una concepción abierta que integra los aspectos más articulados de la vida asociativa con los menos estructurados de la vida cotidiana. La noción de sociabilidad permite "ver emerger la vida asociativa a partir de la vida social informal"3.

El café, en palabras de Agulhon, "es un personaje histórico"4. Desde esta perspectiva interpretativa que demanda estudiar una realidad tal, también la calle y el prostíbulo fueron personajes históricos cuya aptitud asociativa funcionaba como un tejido de conexiones a través del cual amplios sectores podían satisfacer las nuevas necesidades surgidas de las relaciones económicas y sociales del momento, y construir lazos de pertenencia y solidaridad. Aunque, para un emigrado como Herreros, un desarraigado de su tierra que soporta, según sus versos, una "vida sin amor ni hogar", "de miseria y soledad"; que debe, como dice Edwar Said, ingeniárselas en nuevos entornos con una "mezcla de creatividad y tristeza", los espacios de sociabilidad representan, más que una posibilidad de integración pura, un medio de supervivencia donde, al mismo tiempo, puede reducir el distanciamiento y la inconformidad que le proporciona su mirada de referente doble al contrastar permanentemente un espacio de procedencia con otro de llegada; reducir con una manera de "ubicuidad imposible", la "doble ausencia" de la que nos habla Abdelmalek Sayad, que se instala entre "las ilusiones del emigrado" y "los padecimientos del inmigrado" .

Las orientaciones historiográficas centradas en el análisis de las sociabilidades y la opinión pública, influidas fundamentalmente por Maurice Agul-

3 Maurice Agulhon, "La sociabilidad como categoría histórica", en Formas de sociabilidad en Chile, 1840-1940 (Santiago de Chile: Fundación Mario Góngora, 1992), 1-10. Un análisis del concepto y sus usos historiográficos, en Pilar González Bernaldo de Quirós, "La sociabilidad y la historia política”, Nuevo Mundo Mundos Nuevos [En línea]. URL: http//nuevomundo.revues.org/24082; y Stéphane Van Damme, "La sociabilité intellectuelle. Les usages historiographiques d'une notion", Hypothèses, 1 (1997): 121-132.

4 Maurice Agulhon, El círculo burgués. La sociabilidad en Francia, 1810-1848 (Buenos Aires: Siglo XXI, 2009), 37.

5 Edward Said, Reflexiones sobre el exilio (Barcelona: Mondadori, 2005), 17; y Abdelmalek Sayad, La doble ausencia. De las ilusiones del emigrado a los padecimientos del inmigrado (Barcelona: Anthropos, 2010), 183-198. 
hon y Jürgen Habermas, han tenido en Argentina durante las tres últimas décadas, al menos tres líneas de actuación: en relación con la vida política del siglo XIX, con los sectores populares y la élite social, y con las asociaciones étnicas. La noción de sociabilidad se ha ligado a los estudios de la historia política y la historia social, pero no tanto al concepto de cultura, el concepto que es tenido en cuenta aquí y nos permita hablar por tanto de "sociabilidades culturales".

Academias, sociedades profesionales, salones, ateneos, círculos, cafés literarios, librerías, zonas callejeras, prostíbulos y otras formas de reunión surgieron en el siglo XIX argentino en relación, sobre todo, a las nuevas dinámicas políticas y económicas que facilitaban su establecimiento social y cultural. Dinámicas que fomentaron, mediante corrientes ideológicas positivistas de desarrollo y progreso civilizado, la recepción de inmigrantes que podían colonizar territorios y mejorar la industria. A partir de 1880, a medida que se iban consolidando las instituciones políticas, Argentina entró en un periodo de inmigración masiva que se prolongó hasta 1914.

En este contexto social es cuando el poeta español Pedro Herreros llega a Buenos Aires. Un momento de transición secular en el que se estaba perfilando la emergencia de un mercado cultural especializado, la normalización de los estudios universitarios y sus institutos de investigación, y la profesionalización del escritor, el periodista, el historiador y el crítico literario. Institucionalización y profesionalización que dieron lugar a iniciativas culturales ligadas a proyectos editoriales, a publicaciones periódicas y grupos asociados a ellas como fueron La Nación, El Hogar, Caras y Caretas, Mundo Argentino, Plus Ultra, Proa y Nativa, revistas y diarios en los que participó Herreros.

Pedro Herreros nace en 1890 en la pequeña población española de Arnedo, de la que se llamaba por aquel entonces Provincia de Logroño, actual Comunidad Autónoma de La Rioja. Huyendo de un medio rural que

6 Paula Bruno (Dir.), "Introducción” a Sociabilidades y vida cultural. Buenos Aires, 1860-1930 (Buenos Aires: Universidad Nacional de Quilmes, 2014), 9-10. Esta introducción (9-26) muestra un panorama historiográfico heterogéneo de la cuestión, en diferentes periodos de la historia argentina y con distintas miradas. 
hacía difícil la promoción social y económica, y escapando, sobre todo, del temor a ser llamado a quintas cuando en España se estaban dando los conflictos militares de Filipinas (1896-98), Puerto Rico (1898) y Cuba (1895-98), llega a Buenos Aires en 1908.

En 1928 contrajo matrimonio con Ernestina Rosa Cerda Delgado, natural de El Puesto, localidad del Departamento Tinogasta, provincia argentina de Catamarca. Tuvo dos hijos (Eduardo Pedro, en 1929, y Nelly, en 1931) y desde 1935, por problemas de salud, se radicó en las cercanías de la ciudad de Córdoba. Al poco tiempo, un 14 de octubre de 1937, murió. Su vida fue breve (47 años), pero su obra poética contó al menos con un estimable de ocho títulos y fue adscrito a un movimiento literario de importantes repercusiones literarias que se denominó Sencillismo, donde destacó el conocido poeta argentino Baldomero Fernández Moreno, íntimo amigo del poeta español. Su actividad cotidiana, envuelta durante mucho tiempo en penurias económicas, siempre giró alrededor de unas amistades que crearon círculos artísticos, de sus proyectos literarios y de sus colaboraciones en distintos medios periodísticos.

Antes de contraer matrimonio, Herreros anduvo por todas las calles de Buenos Aires durante 20 años; fue un perfecto conocedor de los espacios de sociabilidad artística e intelectual que se crearon en la palpitante ciudad de principios del siglo $\mathrm{XX}, \mathrm{y}$ de las numerosas figuras que la poblaron, muchas veces por ser amigo de ellas.

La poesía, la literatura y el arte en general, propulsaron la creación de una esfera pública de debate y de crítica, que construyó un espacio de doble vertiente fijado, primero por la producción, circulación y apropiación de lo escrito, cuya definición está vinculada a las prácticas solitarias de escritura o de lectura; y luego por las nuevas formas de sociabilidad, donde los sujetos privados hacen ejercicio público de su razón mediante la discusión y la crítica de asuntos literarios y asuntos políticos en general, y crean un marco público que se manifiesta en establecimientos privados como los cafés, clubes, salones, sociedades literarias o librerías ${ }^{7}$.

7 Roger Chartier, Cultura escrita, literatura e historia. Conversaciones con Roger Chartier (México DF: Fondo de Cultura Económica, 2006), 86-87. 
Desde esta consideración social, que mostraba los nuevos espacios surgidos de nuevas aptitudes ante lo público y relacionaban lo político y lo cultural con la difusión del ocio, este texto es una versión resumida y fragmentada de una investigación mayor que estudia las relaciones existentes entre la obra de Pedro Herreros y las experiencias vivenciales que lo llevaron a frecuentar espacios de reunión pública. Sus poemarios, por tanto, y la bibliografía referente a los aspectos políticos, sociales y literarios que atraviesan la época en la que vivió en Argentina, han sido nuestras principales fuentes de información. Historia social y cultural confluyen en el conjunto de nuestro estudio, que inevitablemente pasa por la constatación y la descripción de las formas de sociabilidad en las que el poeta español se vio inmerso y es aquí el aspecto en el que ponemos énfasis.

Para ello, de entre la densidad historiográfica que habla de la actividad asociativa y sus tramas conectivas, nos hemos valido principalmente de obras básicas que se centran en el ámbito bonaerense y ponen en práctica los conceptos y la metodología del campo historiográfico de las "sociabilidades culturales" durante el periodo tratado influido por autores como los mencionados (Habermas y Agulhon) y en menor medida por Roger Chartier y Georg Simmel ${ }^{8}$. Textos como los de José Luis Romero (Latinoamérica: las ciudades y las ideas), Beatriz Sarlo (Una modernidad periférica: Buenos Aires 1920 y 1930), Rafael Alberto Arrieta (La ciudad y los libros. Excursión bibliográfica al pasado porteño), Adolfo Prieto (Sociología del público argentino), Albert Londres (El camino de Buenos Aires: La trata de blancas), Pablo Ansolabehere (La vida bohemia en Buenos Aires, 1880-1920: lugares, itinerarios y personales), Sandra Gayol (Sociabilidad en Buenos Aires: hombres, honor y cafés: 1862-1910) y la dirigida por Horacio Vázquez-Rial, Buenos Aires, 1880-1930. La capital de un imperio imaginario, han sido referencias obligadas para poner en sintonía la calle, el café y el prostíbulo con el universo asociativo de ciertos grupos de intelectuales de la vanguardia y la bohemia bonaerenses donde Pedro Herreros se desenvolvió.

8 Roger Chartier, Espacio público, crítica y desacralización en el siglo XVIII. Los orígenes culturales de la Revolución Francesa (Barcelona: Gedisa, 2003) y Georg Simmel, Sociología. Estudios sobre formas de socialización (Madrid: Alianza, 1986). 
Pero nuestro esencial propósito no es tanto el de descubrir esas sociabilidades, aunque sí en la obra poética de Herreros, sino el de, como decimos, definirlas y ponerlas en relación con los versos de un poeta español emigrante en Buenos Aires que nunca hasta ahora ha sido estudiado. No es frecuente, por otro lado, reparar en la poesía para estudiar las formas de sociabilidad de una determinada época. Menos frecuente todavía, reparar en la obra poética de un autor desconocido como sigue siendo Pedro Herreros. Los rasgos autobiográficos que recorren su obra, centralmente los poemarios Buenos Aires grotesco y otros motivos (1922), Poemas egotistas (1923) y Las trompas de Falopio (1924) 9 , muestran tres espacios que, solo o en compañía, el poeta habitó como si fuera parte de ellos mismos: la calle, el café y el prostíbulo. Por ello, la mirada de Herreros no será la observación crítica que juzga a distancia; sus experiencias vivenciales definen a un emigrante que en difíciles condiciones económicas y sin familia, tuvo que adaptarse a vivir en la calle, y por su condición autoafirmada de poeta frecuentó los círculos literarios y ambientes libreros del Buenos Aires de la época. Son algunas de estas marcas autobiográficas las que a través de su poesía recorremos aquí para describir el contexto político-social en que dichos espacios de sociabilidad se daban y la variedad de personajes que por ellos desfilaban.

\section{El DESENGAÑo DE UN EMIGRANTE}

A inicios del siglo XX, Argentina mantenía un crecimiento económico que seguía alentando a la emigración europea, pero a finales de la primera década se detecta ya un cambio en la coyuntura económica. Pedro Herreros llega a Buenos Aires en 1908 y al poco tiempo, en mayo de 1909, presencia una convocatoria de huelga general que acuarteló a las tropas gubernamentales. En 1910 comienzan a celebrarse en toda la Argentina los fastos del Centenario de la Emancipación que exhiben ante el mundo la imagen de un país que pretendía ser rico internacionalmente y una potencia en la América Latina. Sin embargo, a lo largo de 1910 se experimentó una pa-

9 Pedro Herreros, Buenos Aires grotesco y otros motivos (Buenos Aires: Editorial Samet, 1922); Poemas egotistas (Buenos Aires: Talleres Gráficos Damiano, 1923) y Las Trompas de Falopio (19151923) (Buenos Aires: Sagitario, 1924). 
ralización progresiva de la actividad comercial y comenzaron a proliferar noticias alarmantes sobre el paro o el subempleo en la capital argentina.

Desde finales de 1912, la crisis se generalizó en todos los sectores económicos. El Diario La Rioja, en ese mismo año, hablaba de "un desempleo masivo de españoles que vagan por las calles escuálidos y hambrientos, sin otro deseo que retornar". El deterioro de la situación social se agudiza y en 1914, en el mismo Diario leemos:

La situación es peligrosa para ese enorme número de trabajadores que después de haber confiado en la virtud prolificadora de la tierra argentina se ven obligados a reconocer el engaño en que han vivido ante las obras de los hombres, tan opuestos a la bella promesa de la tierra... ${ }^{10}$.

Este desengaño personal del emigrante es expresado por Pedro Herreros en el poema, de sabor amargo, titulado La tragedia de ver, del libro Poemas egotistas (1923): "[...] me lancé a conquistar el Nuevo Mundo...// Y aquí vino la lírica locura de soñar/ Y fue bien triste el despertar..."11. Es un libro que recoge 78 poemas. La gran cantidad de composiciones que contiene, aunque algunas de ellas sean muy breves, y la poca distancia temporal que media entre su anterior publicación en 1922 de Buenos Aires grotesco y otros poemas, y esta de 1923, revelan que un número elevado de estos "poemas egotistas" se han escrito mucho antes de su fecha de edición. Poemas egotistas, sin dejar de incluir el humor sano característico del poeta, mantiene mayoritariamente un tono trágico y desesperanzado al hablar de su situación personal como emigrante y de un país que no ofrece protección al desvalido ${ }^{12}$ : “[...] Además, ¿¿qué interesa mi vida silenciosa/ a este Buenos Aires de negocio y de estruendo?!// En esta gran ciudad/ yo sé que estoy expuesto/ a morir cualquier día/ como un perro".

10 Diario La Rioja, año XXIV, No. 7464, p. 1 (31-XII-1912) y Diario La Rioja, año XXVI, No. 7906, p. 1 (25-III-1914). Citados en Pedro A. Gurría García y Mercedes Lázaro Ruiz, Tener un tío en América. La emigración riojana a ultramar (1880-1936) (Logroño: Instituto de Estudios Riojanos, 2002), 70-71 y 107.

11 Pedro Herreros, Poemas egotistas, 12.

12 Pedro Herreros, Poemas egotistas, 51 (Como un perro). 
Con ciertas señales de protesta social ("Divino de intuición/ quise ver y vi en la vida./ ¡Y al verla tan corrompida/ se llenó mi corazón/ de asco y de indignación!"), su desengaño ("la tragedia de ver"), con “el alma entristecida" y "la juventud perdida", hace pedir a Dios lo libre "de la amarga tragedia de mi vida". Desgracia, tristeza, amargura, pobreza, angustia, tragedia, dolor, desesperanza, son términos que se suceden en este libro que refleja la realidad vivencial por la que estaba atravesando el poeta ${ }^{13}$.

Por medio de un alarde humorístico, o una "impresión sintética", como diría Fernán Silva Valdés ${ }^{14}$, cuando más desesperanzado se encuentra ("Mi amargura es la de un hombre/ traspasado de tristeza/ sin más esperanza que/ ser feliz bajo la tierra"), este es su Balance al terminar el año: "Fin de año. Rotas/ las medias y las botas" ${ }^{15}$. Pero antes de estos, directos, sinceros y egotistas poemas, Pedro Herreros, en Buenos Aires grotesco y otros poemas (1922), ya había hablado de los dramáticos efectos de la crisis económica que estaban sufriendo los emigrantes en Buenos Aires ${ }^{16}$ :

Dejó su hogar en Castilla

e hizo rumbo a Buenos Aires.

Desembarcó. Y varios años

fue un honrado comerciante.

Ahora anda por el suburbio

-hecho un grasiento "atorrante"-

con su honor y con sus piojos...

¡sin valor para matarse!

En el poema que dedica a Lucette, "amiga", dice el primer verso, del poeta, y prostituta; después de manifestarle que "...esta sociedad corrompida/ te lanzó en la vorágine del mar de la tristeza”, viendo como un consuelo

13 Pedro Herreros, Poemas egotistas, 52 (Invierno).

14 Fernán Silva Valdés, Diario El País (Sección Artes y Letras), Montevideo, 6 de noviembre de 1922, 32.

15 Pedro Herreros, Poemas egotistas, 25 (Desesperanza) y 83 (Balance).

16 Pedro Herreros, Buenos Aires grotesco, 71 (Un indiano...). 
la "pena” en su "corazón”, el poeta pasa a hablar de sí mismo: "Yo también ando hundido en ese mismo mar [...]Yo soy un niño-viejo, trágico y sensitivo,/ que casi no hago más que sufrir y vibrar". Trágico y sensitivo, así es como Herreros asume el oficio de ser poeta para, utilizando las metáforas marinas del mar que hasta allí lo había llevado, fundir en un solo destino las vidas del poeta y de la prostituta: 'Y así, tú, en la galera del triste meretricio,/ y yo, en la frágil barca de la diafanidad,/ somos dos galeotes rumbo a la Eternidad,/ ¡dónde terminará nuestro suplicio!’. Pedro Herreros cuenta ya con 32 años, todavía no ha encontrado ese "amor" que "venga solo y suave", ni condiciones laborales estables: "De todos los que estamos en el bar/ ninguno tenemos hogar". El "cafetín" sigue siendo su "hogar" y su "casa" y cuando "despierta la ciudad" anda "vagando por las típicas calles suburbanas" de Buenos Aires: "Cada puerta que viene es un misterio/ que una emoción, en su interior, me guarda.// Muchas veces, las más, es la emoción/ de creer encontrar... y no hallar nada"17.

A la calle y el café, se le suma el prostíbulo, lugares de sociabilidad elegidos por el poeta que marcan extremos de la vida bohemia. Por un lado los ambientes libreros de calle, y el café, donde la amalgama artística de los grupos se intensifica y se convierte en señal de identidad; y por otro, el prostíbulo, donde también se acude en compañía, pero donde la sociabilidad se resiente y se da paso a la sordidez. No hay aquí, en este espacio de la bohemia la camaradería risueña del café o el restaurante y Herreros pasó de un lugar a otro tal vez por su condición libérrima de bohemio ${ }^{18}$.

\section{LA CALLE}

Buenos Aires grotesco describe la cotidiana realidad del poeta, muy transformado ya respecto a los ingenuos ambientes que mostraba en 1915 El libro de los desenfados. Es un libro que resulta ser un diario de cafés, tabernas,

17 Pedro Herreros, Buenos Aires grotesco y otros poemas, 26 (Marineros), 69 (A Lucette), 70 (Temor) y 83 (La busca).

8818 Sobre los rasgos característicos de la bohemia y sus extremos en el Buenos Aires de la época, Pablo Ansolabehere, "La vida bohemia en Buenos Aires (1880-1920): lugares, itinerarios y personajes", en Bruno, Paula (Dir.), Sociabilidades y vida cultural. Buenos Aires, 1860-1930 (Bernal: Universidad Nacional de Quilmes, 2014), 155-185. 
calles y prostíbulos. Aparecen sus paseos por el paisaje de los bosques del parque de Palermo, por el Parque Lezama, por la Plaza y la Avenida de Mayo, por el Paseo de Julio, espacios rebosantes de autos, coches, teatros, hoteles, floristas, mercaderes, rameras, funcionarios, cines, kioskos, casas de cambio, cafés-concierto, diarios y periodistas, poetas, libros, hambre y atorrantes. Se hacen presentes los tranvías de Lacroze por la Avenida Huergo, los tranvías que van en las sombras abriendo boquetes de luz, la boca del Riachuelo, la Torre de los Ingleses, la Casa Rosada y el Río de la Plata en una mañana de invierno; la flaca costurera y la muchachita que vende mandarinas y bananas en el hueco que forma una puerta cerrada, lo inmigrado y la esclavitud por una calle del barrio sud, el puerto en una noche de verano y en una mañana de niebla, las casas de la isla Maciel y las calles, en fin, "brillantes como lunas de espejos"19.

La ciudad, la condición urbana en los poetas de la época, es recurrente y Borges relaciona a sus fundadores literarios, "los poetas que han trabajado en su endiosamiento, los que sin un sacudón, sin un sobresalto, sin inconveniente alguno edilicio, han hospedado en la eternidad nuestras calles"; habla de Domingo Martinto, Eduardo Wilde, Evaristo Carriego, Marcelo del Mazo y Enrique Banch. Después de comentar el libro de Baldomero Fernández Moreno, Ciudad, concluye su repaso mencionando a poetas contemporáneos como Blomberg, Yunque, Olivari, Raúl González Tuñón y Pedro Herreros ${ }^{20}$.

A partir de 1880 se produjeron en Argentina transformaciones modernizadoras que cambiaron el país: desarrollo urbano, consolidación de la clase media alta, alfabetización, inmigración, aparición y crecimiento de

19 El artículo de Pedro Herreros titulado "El viejo Paseo de Julio", Caras y Caretas, No. 1371 (1925): 96-97. En él describe "si no la muerte definitiva", al menos, "la agonía de un viejo y pintoresco" Paseo de Julio "tan cosmopolita, tan pintoresco y tan henchido de sugestiones y de evocaciones universales", que con las nuevas dinámicas capitalistas de la ciudad se va transformando aceleradamente.

20 Jorge Luis Borges, "La presencia de Buenos Aires en la poesía”, Diario La Prensa, Buenos Aires, 11 de julio de 1926 (s.p.). Nicolás Olivari (El gato escaldado, 1924; La musa de la mala pata, 1926), Raúl González Tunón (El violín del diablo, 1926; Miércoles de ceniza, 1928) y el propio Borges (Fervor en Buenos Aires, 1923) introducen en sus poemas las calles de Buenos Aires: el tranvía, el ómnibus colectivo, referencias a medios de locomoción, figuras o tipos humanos en ambientes deplorables; andanzas por el puerto, el Paseo de Julio, la Boca del Riachuelo; ambientes, hechos y tipos que mezclan lo poético con lo social y la realidad urbana con sus imaginarios. 
una aún incipiente industria cultural. En el poco tiempo de una década se instalaron en Buenos Aires oficinas públicas con decoro y comodidad, el urbanismo ganó en elegancia: plazas, parques y paseos recibían el mismo cuidado que los jardines londinenses; el tenebroso Paseo de Julio se transformó en una amplia avenida con pavimento de madera, desde la Casa Rosada a la Recoleta; la Plaza Constitución se amplió y embelleció; innumerables calles fueron niveladas y nuevamente pavimentadas; las mejoras no olvidaron el parque de Palermo, al que hicieron llegar la luz eléctrica. Pero la obra de mayor magnitud, proyectada cuando gobernaba Miguel Ángel Juárez Celman (1886-1890), fue la Avenida de Mayo ${ }^{21}$.

Sin embargo, los procesos socioeconómicos iniciados en las dos últimas décadas del siglo XIX, no solo alteran la constitución urbana de Buenos Aires, sino los modos de convivencia de sus habitantes. Esta interesa como espacio físico y como mito cultural: "La metáfora de la ciudad-puerto". Ciudad y modernidad se entrelazan ${ }^{22}$. La ciudad como símbolo y escenario material que exhibe los cambios sociales e ideológicos de una modernización acelerada al ritmo de las nuevas tecnologías de producción y de transporte. La capital se sitúa entonces en el referente de los proyectos institucionales del siglo XIX: el mundo rural vencido por la gran ciudad, por una mayor y nueva base demográfica y un progreso económico que va diseñando una nueva realidad.

Durante los años 20 y 30 del siglo XX se hace proclive a los cruces culturales y sociales sustentados en el cambio demográfico. La heterogeneidad (social, urbana, artística, arquitectónica) del espacio público de la calle como lugar común de ocupación simbólica, establece un sistema fluido de circulación y préstamos o intercambios estéticos o culturales y en el campo de la literatura se constata una fuerte presencia de un público medio y

21 Rafael Alberto Arrieta, La ciudad y los libros. Excursión bibliográfica al pasado porteño (Buenos Aires: Librería del Colegio, 1955), 170. Arrieta sigue la obra del viajero inglés Thomas A. Turner, que residió en Buenos Aires de 1885 a 1890: Argentina and the Argentines. Notes and impressions of a five years' sojourn in the Argentine Republic, $1885-1890$ (London: Swan Sonnenschein \& Co., 1892).

22 La caracterización de las ciudades burguesas y las ciudades masificadas respecto a las ideas que atraviesan las relaciones entre individuo y sociedad está dada en la obra de José Luis Romero, Latinoamérica: las ciudades y las ideas (Medellín: Universidad de Antioquia, 1999 (1976), 295-471. 
popular surgido del proceso exitoso de la alfabetización para el que se producen colecciones literarias (folletines sentimentales, magazines), literatura de kiosko y revistas que van desde la literatura de "placer y consolación" hasta la literatura propagandística, pedagógica y social ${ }^{23}$.

En el gran espacio urbano que considera la calle lugar común, que hace lo diferente visible, que confunde lo público con lo privado, que permite una gran variedad de cruces culturales y sociales, el anonimato resalta la mirada asombrada o curiosa a gentes, escenas y lugares; potencia el vagabundeo callejero. El poeta argentino Baldomero Fernández Moreno comenta la amistad que tenía con Pedro Herreros en Vida y desaparición de un médico, la segunda parte de sus memorias. Ofrece detalles nimios de ambientes y personajes, de cómo, después de acabar su trabajo como médico, juntos vagabundeaban por las calles de Buenos Aires en busca de las librerías de viejo, de casas de antigüedades y de cines baratos:

"El médico, asustado, daba paso al poeta, que acababa por reunirse con su amigo Pedro Herreros, y se cenaba frugalmente en cualquier lado. Había un almacén en la calle Bolívar, con un comedor donde solíamos acomodarnos entre gente de trabajo, más o menos próspero. Se comía sobre el hule y, si todo era simple, todo era sabroso, y siempre sin apearse de la conversación en torno a libros y a poemas hechos o por hacer. [...] Por muy pocos centavos que tuviéramos, podíamos irnos a dar una vuelta por la calle Lavalle, ya clasificada de feérica [...] Buscábamos los cines más baratos y, si no, ahí estaban las librerías de viejo en que revolviendo estantes y canastos, podíamos echárnoslas de conocedores y eruditos y, a veces, descubrir la pieza rara al alcance o no de nuestros bolsillos. También abundaba la calle en casas de antigüedades. [...] Otras veces, el vagabundeo, desde el Riachuelo a Palermo. Y, por último, ya agotado el vuelo del riojano, pues

23 Beatriz Sarlo, "Modernidad y mezcla cultural", en Buenos Aires, 1880-1930. La capital de un imperio imaginario, Horacio Vázquez Rial (Dir.) (Madrid: Alianza Editorial, 1996), 183-190. Sobre la formación de públicos lectores heterogéneos a través de proyectos editoriales, Adolfo Prieto, Sociología del público argentino (Buenos Aires: Ediciones Leviatán, 1956), 47-85. 
era de Logroño, pese a su figura y compañerismo, se encaminaba a su guardilla" 24 .

Aunque la obra de Herreros ofrezca mayoritariamente ambientes de escenarios populares, no olvida la calle Florida, "la calle de los elegantes", como la llama Rafael A. Arrieta, uno de los paseos, todavía hoy, más comerciales de Buenos Aires. No se olvida en ella, como tampoco en el Paseo de Julio, de los libros ${ }^{25}$ : “Oro, plata y cristales, / flores y librerías, / exposiciones de arte,/ finas zapaterías, / y una acicaladísima/ muchedumbre de iguales" (Florida). En La ciudady los libros, Arrieta expone con magnífico detalle el ambiente librario-callejero que en el último decenio del siglo XIX iba en aumento en la capital argentina. No faltan las referencias a algunas librerías de la calle Florida, como la de Alfredo Cantiello, especializada en el libro italiano. En sus locales de Florida 26, primero, y Bernardo de Irigoyen 946 después, se celebraba casi a diario una tertulia de escritores, periodistas y amigos que presidía el erudito y bibliófilo Pedro Denegri.

En el capítulo dedicado al siglo XX, en uno de los recorridos por las librerías y puestos de ventas de libros propuesto por el autor, cuando ya se acercaba la segunda república española de 1931, aparece, por cierto, el logroñés Martín García, emigrado desde la misma provincia natal donde nació Pedro Herreros, la Provincia española de Logroño. Tenía su librería en Rivadavia, una de las calles que atravesaba Florida. Después de visitar en Florida 32S, el establecimiento del librero y también editor Arnaldo Moen (Arnaldo Moen y Hermano Editores), pasa a la librería del español:

"Tampoco la penumbra que espolvorea el aposento y amortece la policromía de las encuadernaciones se tragará los rasgos del

24 Baldomero Fernández Moreno, Vida y desaparición de un médico (Buenos Aires: Editorial Kapelusz, 1968), 167-169. Baldomero continúa narrando su recorrido en el apartado siguiente, dedicado a la revista Caras y caretas: "Abandonaba a Herreros en la calle y me refugiaba generalmente en Caras y caretas, en aquel primer piso que hervía de versos y de colores, en aquella sala de trabajo, bajo la luz cruda de sus focos y la charla o el mutismo de Mayol, que a ambos extremos hacía. Y a su alrededor, como polluelos, estaban Sirio, Álvarez, Málaga Grenet, o poetas como los hermanos Pérez Valiente, uno de ellos dibujante; Leguina, un escritor español; Eduardo del Saz, que entraba y salía, Castellanos, etcétera" (p. 169).

25 Pedro Herreros, Buenos Aires grotesco, 23 (Paseo de Julio) y 73 (Florida). 
logroñés Martín García. Sonriente, acogedor, en su local de la calle Rivadavia, frente a La Prensa, saluda a quien acaba de entrar, lo palmotea, le anuncia la inminencia de la república en España y le muestra los libros del último correo ultramarino. Se adelanta enseguida el corso Ignacio Morelli, movedizo, cordial, con el mechón entrecano saltándole en la frente: su puerta mira a la plaza del Congreso y su vidriera junta las novedades de Perrin y Zanichelli, de Laterza y Calman-Lévy. El complacido evocador se traslada en un pestañeo a la sala alfombrada de la librería Dante Alighieri -Florida, entre Corrientes y Lavalle- y reanima rostros lejanos entre una vitrina con autógrafos de autores editados por Fratelli Treves y una mesa que exhibe dramas de Bracco, números de Nuova Antologia y los Laudi dannunzianos ilustrados por Karolis"26.

El paseo continúa, a pocos pasos, por Mitchell' Book Stores, y de ahí se dirige a Corrientes, calle todavía angosta, y algunas que otras transversales como Lavalle. La atmósfera de este núcleo callejero es bien descrita por Roberto Arlt en su texto titulado Corrientes, por la noche. Las imágenes son numerosas y la aglomeración de personajes, cosas y escenas es abrumadora. Con una técnica que corresponde a la gran cantidad de imágenes distintas, recurre a la yuxtaposición, como Herreros hizo en poemas de Buenos Aires grotesco como Avenida de Mayo, Paseo de Julio, Lienzo suburbano o Junto al Plata, y al respecto de los libros, Arlt los vivifica tal si se tratara de un elemento más en movimiento: "Más que calle parece una cosa viva, una creación que rezuma cordialidad por todos su poros [...] Vigilantes, canillitas, fiocas, actrices, [...] revendedores [...] cómicos, poetas, ladrones $[\ldots]$ autores, vagabundas, críticos teatrales, damas de medio mundo [...] Y libros, mujeres, bombones y cocaína, y cigarrillos verdosos, y asesinos incógnitos [...] Librerías de viejo y nuevo con volúmenes hinchados de pornografía, junto a la millonésima edición de Martín Fierro"27.

26 Rafael Alberto Arrieta, La ciudad y los libros, 198.

27 Roberto Arlt, "Corrientes, por la noche", en Cuentos y aguafuertes (Buenos Aires: Ediciones LEA, 1994), 133-135. 


\section{El Café}

Autores, editores, impresores, libreros, bibliófilos, novedades literarias, distribuidores; Arrieta dibuja con detalle el panorama de los puestos de venta de libros y de las librerías de la época, que se anunciaban en la prensa local y donde se llevaban a cabo tertulias de escritores. Pero Herreros, a diferencia de estas tertulias, no utilizará para ellas las librerías, sino el café. Buenos Aires grotesco está dedicado a los cafés, en los que claramente ("Cafetín que eres mi hogar y mi casa”), el poeta, entre otras cosas, ha empleado muchas horas a la lectura y a la escritura, retratando la vida de los propios cafés o retratando la vida que a través de sus ventanas transcurría: "Todas las tardes pasa con un paquete enorme/ (Bombachas o pantalones)./ Costurera flaca y joven,/ iqué amargo es el pan que comes!” (La costurera que va a entregar).

Signo de esa dedicatoria es la portada del libro, la caricatura del autor realizada por el artista plástico, ilustrador y caricaturista Antonio Bermúdez Franco, a quien en el mismo libro Herreros dedica un poema. La caricatura, donde aparece en actitud pensativa cubriéndose con la mano derecha su barbilla, es la imagen inaugural de Buenos Aires grotesco y representa la consagración de la vida del poeta frente a la mesa y la taza de café, con el lápiz y el papel siempre dispuestos a utilizarse. El primer verso del libro es este: "Yokohama. Rincón. Lectura", y de inmediato, en su tercer poema, continúa: "Estoy en el Yokohama./ La blanca luz se desparrama/ en el espacio y sobre los clientes". Al Café Yokohama le siguen el Café de La Puñalada, donde se ven los rostros de los "pobres artistas fracasados" que se "fueron a la bohemia", donde "dos bohemios de rostro sibilino/ meditan sobre el plan de una opereta" y no muy lejos, "un feto de poeta/ lee risueñamente al Aretino". Continúa con el Café Paulista, "alto zócalo de roble/ en las paredes blanquísimas" donde el poeta sueña "mientras los ventiladores giran"; con un café entre las calles Perú y Venezuela, donde un rabí de Galilea escribe mientras su pipa humea; el Café de La Cosechera en un día de lluvia a raudales; y el "Rey de los cafés", que, a juzgar por sus mesas "verdes y transparentes/ como espejos de fuentes" que todavía mantiene, era el Café Tortoni. Fundado en 1858, después de sufrir varios 
cambios de ubicación, en 1893 se instala en la Avenida de Mayo 825 con mesas de roble y mármol veteado en verde y blanco ${ }^{28}$.

Frente a los primeros libros de Baldomero Fernández Moreno (Las iniciales del misal, 1915; e Intermedio provinciano, 1916), que nacen al margen de relaciones con figuras de su generación (Enrique Banchs o Alfonsina Storni) y de generaciones anteriores (Lugones) o posteriores (Borges), Ciudad (1917), su tercer libro, se gestó en medio del tejido generacional, entre redacciones periodísticas y cafés, con plena conciencia de los movimientos que se producían simultáneamente al desarrollo de su individualidad. Aunque no fue asiduo a La Cosechera y se mantuvo al margen de bohemias, Fernández Moreno sí tuvo en ese café un lugar para hablar de libros con los jóvenes principiantes. El poeta Luis Cané evoca así esa tertulia:
"Fernández Moreno era
el puntal de la reunión:
nos tomaba la lección
de nuestra canción primera.
Y en torno a su corazón,
y de frente a su amistad
que era dulzura y bondad,
nació una generación" 29 .

Conrado Nalé Roxlo, el conocido escritor bonaerense, premio nacional de teatro en 1945, dedica a Pedro Herreros dos apartados de su Borrador de memorias. En uno de ellos relata el momento en que, hacia 1920, Fernán-

28 Pedro Herreros, Buenos Aires grotesco, 5 (Se lo ha tragado el piso), 7 (Un cura, en el café), 24 (Agua), 50 (En el Rey de los cafés), 62 (Aquí, en La Puñalada), 75 (El café de La Puñalada), 81 (Paulista) y 87 (El hermano de Jesús). Véase también el poema de 1929 de Baldomero Fernández Moreno, titulado Viejo café Tortoni, donde se emplea la misma expresión denotativa de presencia permanente que utilizara Herreros: “... Estoy sentado/ bajo el toldo tirante y empapado/ de este viejo Tortoni conocido". En su antología personal que, según el propio Baldomero, transparenta y prefigura su "Obra Ordenada": Antología, 1915-1940 (Buenos Aires: Espasa-Calpe Argentina, 1941), 42 de la primera sección: Ciudad.

29 Luis Canela (Luis Cané), "Un café de la Avenida", Crítica, Buenos Aires, 4 de octubre de 1940. En César Fernández Moreno, Introducción a Fernández Moreno (Buenos Aires: Emecé Editores, 1956), 149, de donde se extraen también las precedentes observaciones. Cané se refiere a esa generación argentina de 1920 donde se encontraban los hermanos, historiadores y políticos, Julio y Rodolfo Irazusta. 
dez Moreno lleva a Pedro Herreros a La Cosechera ${ }^{30}$. El pintor Quinquela Martín, íntimo amigo de Pedro Herreros y ambos nacidos, por cierto, en el mismo año de 1890, habla de las tertulias de los cafés de la Avenida de Mayo, sobre todo de esta de La Cosechera que el pianista catalán Ricardo Viñes bautizó con el nombre de La Peña.

Un modesto café por cada dos horas de tertulia resultaba un negocio ruinoso para los dueños de La Cosechera, así que, perdido el afecto de estos, La Peña se trasladó al Café Tortoni, donde fueron bien recibidos por su dueño, que por aquel entonces se llamaba Pedro Curuchet. El francés Curuchet les abrió espacio a medida que La Peña crecía y les ofreció unos preceptos que quedaron como lemas del grupo:

Ici no peut causer, dire, boire, avec mesure, et donner de son savoir faire la mesure. Mais seul l'art et esprit, ont le droit de sans mesure se manifester $i c c^{31}$.

La Peña quedó inaugurada oficialmente un día de mayo de 1926 con el propósito de proteger y fomentar las artes y las letras. Se hicieron famosas sus veladas y se ofrecían conferencias, conciertos, festivales poéticos y de danza, representaciones teatrales, exposiciones de pintura, lecturas y comentarios bibliográficos, homenajes, etc. En aquel lugar estuvieron personajes como Pirandello o Josefina Baker; por allí pasaron músicos como

30 Conrado Nalé Roxlo, Borrador de memorias (Buenos Aires: Editorial Plus Ultra, 1978), 153 y 156157. La Cosechera quedaba al lado del antiguo Club del Progreso, entre las calles Perú y Avenida de Mayo: "vasto salón revestido de oscuras maderas y claros espejos, con sus mesas de vidrio con patas de verdosos hierros, con las dos enormes vidrieras que formaban su frente sobre una avenida en la que aún se podía pasear con paso reposado".

31 "Aquí se puede conversar, decir, beber con mesura y dar de su savoir faire la medida. Pero solo el arte y el espíritu tienen el derecho de sin medida manifestarse aquí". Asistentes frecuentes a la tertulia, además del propio Quinquela y Viñes, según la relación que trae Quinquela, fueron también Francisco Osernia, Tomás Allende Iragorri, Antonio González Pintor, Francisco Balbi, Carlos Taralli, Augusto González Castro, Gastón O. Talamón, Isaac Castro, Pascual de Rogaris, Alfredo Schiuma, Juan José de Soiza Reilly, Héctor Pedro Blomberg, José María Samperio, Celestino Fernández, Manuel López Palmero, Atilio García Mellid, Germán de Elizalde, Luis Perlotti, Alejandro S. Tomatis, Juan de Dios Filiberto, Carlos de Jovellanos y Passeyro, Daniel Marcos Agrelo, Rafael de Diego, Miguel A. Camino, Pedro V. Blake, Enrique Loudet, Celestino Piaggio, Manuel López de Mingorance, Gregorio Passianoff y nuestro poeta Pedro Herreros. Intelectuales y figuras de todos los gremios artísticos y los medios periodísticos. 
Arturo Rubinstein, Remo Bolognini o María Luisa Anido; se exhibió la obra de Gutiérrez Solana, Darío Regoyos o Agustón Riganelli; leyeron sus versos Alfonsina Storni, Juana de Ibarbourou, Francisco Luis Bernárdez o Baldomero Fernández Moreno ${ }^{32}$.

Entre 1870 y 1914, Sandra Gayol muestra un ritmo ascendente en el establecimiento de cafeterías. Si en 1870 había 523 locales y en 1878, 649; en 1914 serán 1097. No había asentamiento humano que no contara con la presencia de un café y las zonas prioritarias de localización eran las de la Plaza Principal y la "zona céntrica", que actuaban como imanes ${ }^{33}$. Las prácticas y los ámbitos de sociabilidad de los jóvenes intelectuales y artistas argentinos de aquella época se articulan con frecuencia en torno a cenáculos literarios que habitualmente sostenían discusiones en cafés y banquetes. Sin poder llegar a considerarlos como grupos de bohemia alocados o descontrolados, sí construían redes de conocimiento e intercambio de información informales donde no faltaban editores, periodistas, poetas, pintores, historiadores, intelectuales. Así lo recuerda el historiador y político argentino Julio Irazusta en sus Memorias, en un pasaje donde aparece Pedro Herreros, demostrando así que el poeta riojano era asiduo a muy distintas tertulias de diferentes cafeterías de Buenos Aires:

"En el Royal Keller era donde todos los jóvenes nos encontrábamos con más frecuencia, como un campo neutral. Allí íbamos escritores, pintores, escultores, y trasnochadores de toda denominación. Ernesto Palacio, Conrado Nalé Roxlo, Pablo Suero, Carlos Muñoz (el futuro Carlos de la Púa), Pedro Herreros, y tantísimos otros que no puedo recordar de improviso, llenábamos el local con nuestras discusiones, poniendo en solfa las cosas serias y filosofando sobre las ridículas, como les es habitual a los jóvenes" 34 .

32 Andrés Muñoz, Vida de Quinquela Martín (Buenos Aires: [B. U. Chiesino], 1971), 157-166.

33 Sandra Gayol, Sociabilidad en Buenos Aires: hombres, honor y cafés: 1862-1910 (Buenos Aires: Ediciones del Siglo, 2000), 35.

34 Julio Irazusta, Memorias (Historia de un historiador a la fuerza) (Buenos Aires: Ediciones Culturales Argentinas, 1975), 69. Citado en Karina Vásquez, "De la modernidad y sus mapas. Revista de Occidente y la 'nueva generación' en la Argentina de los años veinte”, Revista Intellectus, Vol. II (2003): 19-20 (www.2.uerj.br/intellectus). 


\section{El prostíbulo}

En Buenos Aires grotesco, Herreros no oculta su amistad con las prostitutas (A Lucette) y habla de Ofelia la Romántica "con el cuerpo nadando entre lujuria/ de borrachos... y babas"; de la tuberculosa del bar; de los proxenetas o rufianes ("Maldice a ese señor que a vivir te condena/ sin sol, sin luz, sin aire, entre hambre y entre pena"; de "la prostituta triste y errante" que "va entre la sombra densa y obscura"; de la "chiquilla traviesa" que "exprime la flor carnal/ con un desprecio brutal/ por la vida... y por la muerte" "35. Pero es en Poemas egotistas (1923), donde el poeta confiesa abiertamente su hábito a los prostíbulos: "¡Yo no tengo otro amor aquí/ que el amor de las cortesanas!" (Lamentación); "Yo, la besaba en la boca/ enamorado y frenético/ / [...] Ya hechos ascuas... y enroscadas las sierpes de nuestros cuerpos/ gastamos toda l'azúcar/ y las mieles del infierno" (Amor).

Por aquellos años, las causas de la abundante prostitución que se estaba dando en Buenos Aires, pueden rastrearse en la estructura capitalista del país, con escasas industrias y un desempleo que arrojaba a la muchedumbre trasplantada a la ciudad al desasosiego. La inmigración masiva, señala Ernesto Goldar, comportó una afluencia altamente mayoritaria de hombres y el consiguiente problema sexual. Argentina tenía en 1869 casi dos millones de habitantes. Entre 1853 y 1930 ingresan seis millones de extranjeros, de los cuales retornaron a sus países de origen casi tres millones al estallar la Primera Guerra Mundial en 1914, cuando el porcentaje de población no argentina ascendía al $30 \%$, en su mayoría italianos y españoles, y solo en la capital representaba entre el 40 y $50 \%$. Los inmigrantes se aseguraban en las ciudades y constituían el $80 \%$ del vecindario adulto en Buenos Aires.

Entre 1857 y 1924, el movimiento inmigratorio comprendía un porcentaje masculino del $70 \%$ y el aporte entre 21 y 40 años representaba el $70 \%$. La tasa de masculinidad a mitad de la segunda década del siglo XX es de un $60 \%$ más a favor de los varones extranjeros sobre los varones nativos.

35 Pedro Herreros, Buenos Aires grotesco, 19 (Lo divino), 20 (La tuberculosa del bar), 28 (Por nacer pobre), 29 (La prostituta), 36 (Flor de carne). 
No eran frecuentes las mujeres entre los inmigrantes y había una diferencia de casi 600 mil a favor de los varones sobre las mujeres. Se produjo una segregación de los nativos hacia el arrabal y de los inmigrantes hacia el conventillo: miseria, alcoholismo, enfermedades y prostitución. Así, se importan prostitutas de Europa (polacas - polacs- y francesas - "franchuchas", "franchutas"-, sobre todo) y se organiza el mercado de burdeles. El arrabal se extendió en rancheríos discontinuos y marginales: contrabandistas, garitos, prostíbulos rudimentarios, casas de juego, cuchilleros... Si en los cuartos de las chinas, negras, pardas, mulatas, mestizas, indias y algunas blancas, la actividad aglutinante era la música (con un repertorio indígena y africano en su etapa pretanguera), la prostitución se convierte en el oficio $\operatorname{cotidiano}^{36}$.

Para el periodista y escritor francés, Albert Londres, que investigó la trata de blancas en el Buenos Aires de la época, la ciudad representaba una metrópli-bazar, donde el puerto era su vida, donde un día tras otro desembarcaban y vertían su exceso de material humano italianos, españoles, polacos, rusos, alemanes:

"Hombres, hombres y más hombres. ¡Deseos!, salvajes flores de la juventud sana: jsoledad!, febril enfermedad de los luchadores solteros; ¡riquezas!, irresistibles tentadoras al pecado hecho carne. Todo esto, todo se mezcla y forma el ambiente de la ciudad. ¡Buenos Aires! Allí desembarcan todos los materiales necesarios para la construcción de una inmensa ciudad que nace. ¡Todos! Hasta el más indispensable: ¡la mujer! [...] La mujer [...] francesa, la ¡Franchucha!"37.

En este contexto social, Herreros publica en 1924 Las trompas de Falopio (1915-1923) que, según Hector Pedro Blomberg, "arman escándalo”

36 Ernesto Goldar, "La mala vida”, en Buenos Aires, 1880-1930. La capital de un imperio imaginario, Horacio Vázquez-Rial, (Dir.) (Madrid: Alianza Editorial, 1996), 228-229.

37 Albert Londres, El camino de Buenos Aires (La trata de blancas) (Santiago de Chile: Editorial Ercilla, 1936), 56-57. 
en Buenos Aires ${ }^{38}$. El paréntesis a continuación del título indica que son poemas escritos a partir de 1915, confirmando así el cambio vivencial (y poético) que el poeta experimenta justo después del año de su primera publicación. Las trompas de Falopio está dedicado, con generalidad, "A las prostitutas". Después de un "Frontispicio" que ofrece el juicio moral que al poeta le merece la prostitución, el poema que abre el libro (La prostituta) ya se había dado a conocer dos años antes en Buenos Aires grotesco y otros motivos $^{39}$. Con un sentido de carácter social y moral, continúa el poema titulado La fuente de la muerte:

Hay un barrio a la orilla de esta inmensa ciudad

De groseros prostíbulos y de casas inmundas.

Es un conglomerado de vidas vagabundas

Y seres desahuciados de la vil sociedad.

En él, triunfa la sífilis y estraga la morfina.

Es un foco terrible de miseria y neurosis.

En él, florece el crimen, se nutre la clorosis,

y envenena la cocaína.

$[\ldots]$

El poeta se está refiriendo al barrio de La Boca. Lo dice más adelante en La chica de los pechos más lindos: "¡Cómo no sonreírse si tenía/ los pechitos más lindos de La Boca!".

La legislación que reglamentaba la prostitución en el municipio de Buenos Aires comenzó a formalizarse a comienzos de 1875. Desde entonces, con modificaciones introducidas por ordenanzas posteriores, durante casi 60 años existió en la ciudad el régimen de la prostitución legislada A finales

38 H.B. [Héctor Blomberg], "Damos noticias de Pedro Herreros, poeta dócil a las emociones simples y a los trastornos de su vida pintoresca", en La literatura argentina. Revista bibliográfica, vol. 2, Lorenzo J. Rosso (Buenos Aires: Talleres Gráficos argentinos L. J. Rosso, 1929), 132.

39 El Frontispicio reza de esta manera: "La Prostitución es la afrenta ignominiosa y sucia que tiene sobre el alma y sobre el cuerpo la envilecida Humanidad". Del mismo Buenos Aires grotesco y otros motivos, incluye en Las trompas de Falopio, los poemas Por nacer pobre y Lo divino, este último con cambios formales y sustituyendo el nombre de Ofelia la Romántica por el de Antonia la Romántica, menos poético y más abiertamente real. 
de siglo ya eran famosos los barrios de Constitución, la esquina de Junín y Lavalle, el barrio de los prostíbulos de polacas, La Boca y Dock Sur. En La Boca, hasta después de 1910, los lenocinios se situaban junto a cantinas y "cafés de camareras" 40 por las calles Pinzón, Gaboto, la zona ribereña y las calles adyacentes. La esquina de Suárez y Necochea era el eje de la vida nocturna. El arrabal era habitado por el arquetipo del malevaje suburbano, el proletariado harapiento dispuesto a delinquir: el "malevo" orillero, la mendicidad, la infancia desamparada, los delincuentes profesionales y los rateros, que hablan una jerigonza enrevesada y pintoresca, el "lunfardo".

A fines de la primera década del siglo XX, el extremo ambiente dedicado a la prostitución estaba en La Boca. Aparecen tipos como el rufián, quien hace el tráfico con las mujeres públicas, las instala en casas de tolerancia u organiza su trabajo en la calle. En los cafetines, las polacas hacían parejas para el baile, ocupaban los burdeles de dos pesos y la semioscuridad de los palcos de los cinematógrafos donde se daban películas pornográficas: "Pianola y cine obsceno/ en un ambiente cínico y canalla./ Príapo triunfa en viles recursos femeninos/ o en lujuria y carnaza”, dirá Herreros en el poema El farol colorado ${ }^{41}$.

La Boca era el reino de los polacs (polacos, rusos, tchecos, que trafican con las judías de Polonia), y allí se encontraba lo que, según Albert Londres, testigo presencial, daba carácter al barrio, lo que hacía a los polacs firmar contratos en las chozas israelitas de Polonia: la casita de La Boca, algo "insospechado" para el periodista francés, que describe así:

"En estas casitas, la sala de recibir es el patio. Un patio iluminado con un cabo de vela. No encuentro más semejanza con este patio que la de los corredores secretos de los fumadores de haschish

40 Las "milongas", a principios de siglo, eran antesalas del "cabaret". Una institución originaria del cabaret (y de la prostitución) es el Café de Camareras, que derivaba de las "brasseries" (cervecerías francesas) y se caracterizaba por el servicio que era realizado por mujeres.

41 El Farol colorado (un "turbio atracadero" en Isla Maciel, un barrio de Dock Sud) está descrito inmejorablemente en la conocida letra de tango de la canción homónima El Farol colorado, de Enrique Domingo Cadícamo (1900-1999), poeta y autor de otras famosas letras de tango como La casita de mis viejos o Nostalgias. 
del Cairo. Ni una palabra, ni un gesto. Los hombres no están en cuclillas, están apoyados en la pared. Esperan humildes pacientes, resignados, como los pobres a la puerta de un centro benéfico

$[\ldots]$

Hay una guardiana, sin otra misión que dar un silbido en caso de disputa. Entonces acude el vigilante, un vigilante a quien el chulo da dos pesos diarios [...]

¡La guardiana! Es una china muy vieja, que ronca en una jaula, de mal humor, con un hueso de pollo y una cáscara de banana en las rodillas $[\ldots]$

Todos esperan con recogimiento. Nadie mira a su vecino. Los ojos se dirigen al suelo, sin levantarse más que cuando aparece la sacerdotisa. En ella coinciden las miradas, para volver al suelo cuando cierra la puerta. En ciertas épocas, la puerta se cierra setenta veces al día. No exagero. Estas son las polacas, que cumplen el contrato para salvar el honor de la familia"42.

En 1910, cuando la oligarquía liberal porteña organiza los festejos del Centenario de la Emancipación, las prostitutas francesas invaden la Argentina. Los tiempos de la segunda década del siglo XX fueron gloriosos para los caftenes (proxenetas) franceses que llegaban de París o Marsella: grandes casonas con 18, 20 y hasta 25 mujeres. Después de 1919 se institucionaliza el prostíbulo de una sola mujer y una madama que no debe tener menos de 45 años. Las prostitutas francesas monopolizan este tipo de establecimiento. Los maquereau (los macrós franceses) llenan la ciudad de maisons français (casas francesas) y organizan todo lo relativo al negocio. El centro de operaciones de los macrós era la trastienda de la Librería Francesa, en Cerrito 445. Por la tarde, en pequeños grupos las prostitutas se reunían en los cafés de la calle Esmeralda, en el entrepiso del Pasaje Güemes y en la

42 Albert Londres, El camino de Buenos Aires, 109-110. 
llamada "Manzana Trágica", situada entre Esmeralda, Lavalle, Suipacha y Corrientes ${ }^{43}$.

Cuando Pedro Herreros llega a Buenos Aires en 1908, la trata de "esclavas blancas" a escala internacional ("Tú nunca gozarás de una buena salud, / oh triste flor de esta moderna esclavitud" "4 y la instalación de los lupanares de hasta 50 mujeres, ya llevaba dos décadas desarrollándose; decayendo por ello el sistema de explotación doméstica de la prostitución, la empresa del cafiolo y la mina. Las trompas de Falopio se adapta completamente a estos ambientes de prostitución y relata, con la "piedad sincera" que el poeta siente por las prostitutas, la experiencia de numerosos recorridos por los prostíbulos bonaerenses. Describe escenarios (Habitación de prostíbulo): "Al óleo y malo: Yago, Desdémona y Otelo,/ en la escena del pañuelo.// Un armario de luna biselada./ Y al lado, en el rincón, la toalla colgada.// La estufilla y la pava. Frascos y escupideras./. / Y en las paredes varios retratos de rameras.//Una mesa de noche. Dos sillas rotas./. / Y la cama manchada del barro de las botas".

Describe ambientes y momentos de un lugar que por la gran afluencia de gentes y la compañía ("el pintor") de la que habla, revestía las características de otro espacio de sociabilidad y funcionaba como tal, cuando acude a visitar "la casa de la mujer vendida", donde "la luz en el zaguán del queco está encendida” (Los arrojados delparaíso): “[...] Suena el timbre. El visillo lo corre la alcahueta ${ }^{45}$./ Adelante el pintor y el poeta.// Marineros de Londres o de Bremen/ y un nauseabundo olor a semen.// Ya viene la exprimida pecatriz;/ La triste ordeñadora del amor infeliz [...]”.

Nueve años, que van de 1915 a 1923, son más que suficientes como para entablar confianza y llegar a conocer algunas intimidades: "La Polaca, esta tarde,/ recibió un telegrama: "Muertas madre y hermana"./ La guerra entró en su casa [...] Hace diez años que no las veía/ porque se fue de casa

43 Sobre estas localizaciones aquí referidas y otras cfr. Ernesto Goldar, "La mala vida", 241-248.

44 Pedro Herreros, Buenos Aires grotesco y otros motivos, 28 (Por nacer pobre).

45 De acuerdo a la categoría de la prostituta, algunas estimaciones de la época daban como ingreso diario las siguientes cifras: cocotte, 100 pesos; cabaretera, 30; prostituta clandestina, 20; girante, 15; y alcahueta, menos de 5 . 
embarazada" (El telegrama); "Cuando la Bilbaína era virgen, tenía diecisiete años y pesaba setenta y dos kilos [...] A la Bilbaína le gustan mucho la historia natural y la astronomía" (La Bilbaína).

Sin olvidar a los "cultivadores del ano" del Paseo de Julio, por el libro desfilan numerosos tipos que llenaban estos nuevos lugares de sociabilidad como el inmigrante español y viejo, como el marido brasileño que "viene e medio abrochar", como el señor "muy galán, muy respetable y muy cínico", los marineros ingleses y alemanes, "el gran catedrático/ de la timba carreril", o el gallego "canflinflero y fuñador". En esta "selva de falos erguidos,/ palpitantes y enrojecidos,/ rumbo a las grutas de rosicler", el poeta nos advierte ("Ya lo sabes, lector"), que "aquí hay mujeres/ de todo el universo". Y, efectivamente, no falta poema para cada una de ellas: $A$ una árabe, Una criolla, La polaca, Amor de negra, Lucette la francesa, La bilbaína, La catalana y La gallega.

\section{Conclusión}

Pedro Herreros fue testigo y partícipe directo del ambiente literario de las tres primeras décadas del siglo XX bonaerense, una época de transformaciones sociales fundamentales para innovar en todos los terrenos artísticos. Es una figura, por tanto, la del poeta español, que inevitablemente nos conduce al estudio del contexto histórico argentino y de sus relaciones con escritores fundamentales de la literatura argentina de la época.

Su obra poética describe a menudo tres lugares de habitabilidad social: la calle, el café y el prostíbulo. Constatar y describir estas formas de sociabilidad permite abordar la configuración y el desarrollo de grupos culturales en conexión al contexto histórico que los origina, y desvelar la cohesión de las generaciones en relación a las redes y lugares de sociabilidad como rasgos inherentes de la vida social. Por las inevitables relaciones entre ámbitos de sociabilidad y el mundo de la cultura escrita en sus manifestaciones de producción material de lo impreso y sus prácticas lectoras, conocer las dinámicas de la sociabilidad nos aproxima a formas de actuación colectiva que llevaban a cabo escritores, editores, libreros, el mundo artístico en general, e instituciones o lugares públicos y privados, como fueron los dis- 
tintos círculos literarios reunidos en cafeterías o librerías, que posibilitaban la creación artística, la lectura individual y grupal, y la discusión pública.

Si Fernández Moreno en el callejeo era consciente de la fragilidad de una existencia que le movía al acto re-creador, el despertar de Pedro Herreros en una ciudad de emigrados como él, en la que soportó una difícil vida, le hace reconocer la realidad de una existencia marginal que no se integra en el sistema de la gran ciudad. Sin ser clasificado como poeta anarquista, comunista o socialista; sin una adscripción política definida, Herreros sí sintió el desequilibrio social y de él escribió con aspereza a partir de su segundo poemario publicado, Buenos Aires grotesco y otros motivos (1922). A partir de ahí, su obra se envolvió de marcas autobiográficas que describen su realidad vivencial en las calles, cafeterías, librerías y prostíbulos de la capital argentina.

La escritura autobiográfica no se reduce solo a las biografías, autobiografías, memorias, diarios, correspondencias, cuadernos de viaje. La poesía de Pedro Herreros, todavía hoy una gran desconocida, nos revela así que es posible también extraer de este género literario, rasgos autobiográficos que pueden ponerse en consonancia con la realidad social del momento y, en este caso, con las nuevas formas de sociabilidad que iban surgiendo, donde, alrededor de "lo escrito", se daba cabida a redactores de prensa, editorialistas, literatos e intelectuales. También las señales autobiográficas de una obra modesta como la de Herreros, apoyan la reconstrucción histórica de una época y desvelan matices desde lo marginal, desde la difícil, tal vez nunca conseguida, integración del poeta en el mercado capitalista de la gran ciudad moderna.

\section{Bibliografía}

Agulhon, Maurice. “La sociabilidad como categoría histórica". En Formas de sociabilidad en Chile, 1840-1940. Santiago de Chile: Fundación Mario Góngora, 1992.

Agulhon, Maurice. El círculo burgués. La sociabilidad en Francia, 18101848. Buenos Aires: Siglo XXI, 2009. 
Ansolabehere, Pablo. "La vida bohemia en Buenos Aires (1880-1920): lugares, itinerarios y personajes". En Sociabilidades y vida cultural, editado por Paula Bruno. Buenos Aires, 1860-1930. Bernal: Universidad Nacional de Quilmes, 2014.

Arlt, Roberto. Cuentos y aguafuertes [Estudio preliminar, notas y vocabulario de Teresita Frugoni de Fritzsche]. Buenos Aires: Ediciones LEA, 1994.

Arrieta, Rafael Alberto. La ciudad y los libros. Excursión bibliográfica al pasado porteño. Buenos Aires: Librería del Colegio, 1955.

Blomberg, Héctor [H.B.]. "Damos noticias de Pedro Herreros, poeta dócil a las emociones simples y a los trastornos de su vida pintoresca”. En La literatura argentina. Revista bibliográfica, Vol. 2, Lorenzo J. Rosso. Buenos Aires: Talleres gráficos argentinos L. J. Rosso, 1929, 132. Borges, Jorge Luis. "La presencia de Buenos Aires en la poesía”. Diario La Prensa. Buenos Aires, 11 de julio de 1926.

Bruno, Paula (Dir.). Sociabilidades y vida cultural. Buenos Aires, 18601930. Buenos Aires: Universidad Nacional de Quilmes, 2014.

Coser, Lewis A. Hombres de ideas. El punto de vista de un sociólogo. México DF: Fondo de Cultura Económica, 1968.

Chartier, Roger. Espacio público, crítica y desacralización en el siglo XVIII. Los orígenes culturales de la Revolución Francesa. Barcelona: Gedisa, 2003.

Chartier, Roger. Cultura escrita, literatura e historia. Conversaciones con Roger Chartier. México DF: Fondo de Cultura Económica, 2006.

Fernández Moreno, Baldomero. Vida y desaparición de un médico [Estudio preliminar y notas de Alfredo Veirave. Edición dirigida por María Hortensia Lacau]. Buenos Aires: Editorial Kapelusz, 1968.

Fernández Moreno, Baldomero. Antología, 1915-1940. Buenos Aires, Espasa-Calpe Argentina, 1941.

Fernández Moreno, César. Introducción a Fernández Moreno. Buenos Aires: Emecé Editores, 1956.

Gayol, Sandra. Sociabilidad en Buenos Aires: hombres, honor y cafés: 1862-1910. Buenos Aires: Ediciones del Siglo, 2000.

Goldar, Ernesto. "La mala vida". En Buenos Aires, 1880-1930. La capital de un imperio imaginario, Horacio Vázquez-Rial (Dir.). Madrid: Alianza Editorial, 1996. 
González Bernaldo de Quirós, Pilar. "La sociabilidad y la historia política”. Nuevo Mundo Mundos Nuevos [En línea]. URL: http//nuevomundo.revues.org/24082.

González Tuñón, Enrique. “De cómo Pedro Herreros logró agotar 5.000 ejemplares de su libro Poesía pura”. Diario Crítica, lunes 31 de enero de 1927.

Gurría García, Pedro A. y Lázaro Ruiz, Mercedes. Tener un tío en América. La emigración riojana a ultramar (1880-1936). Logroño: Instituto de Estudios Riojanos, 2002.

Habermas, Jürgen. Historia y crítica de la opinión pública. México DF: Gustavo Gili, 1994 [1962].

Herreros, Pedro. El libro de los Desenfados. Contiene además este pequeño volumen, versos sobre otros asuntos, que pueden servir de provechoso pasatiempo a quien lo leyere. Buenos Aires: Imprenta de José Tragant, 1915.

Herreros, Pedro. Buenos Aires grotesco y otros motivos. Buenos Aires: Editorial Samet, 1922.

Herreros, Pedro. Poemas egotistas. Buenos Aires: Talleres gráficos Damiano, 1923.

Herreros, Pedro. Las Trompas de Falopio (1915-1923). Buenos Aires: Sagitario, 1924.

Herreros, Pedro. El viejo Paseo de Julio. Caras y caretas, 10 de enero de 1925, No. 1371, 96-97.

Londres, Albert. El camino de Buenos Aires (La trata de blancas). Santiago de Chile: Editorial Ercilla, 1936.

Muñoz, Andrés. Vida de Quinquela Martín. Buenos Aires: [B. U. Chiesino], 1971.

Nalé Roxlo, Conrado. Borrador de memorias. Buenos Aires: Editorial Plus Ultra, 1978.

Olivari, Nicolás. El gato escaldado, 1924.

Prieto, Adolfo. Sociología del público argentino. Buenos Aires: Ediciones Leviatán, 1956.

Romero, José Luis. Latinoamérica: las ciudades y las ideas. Medellín: Universidad de Antioquia, 1999 [1976].

Said, Edward. Reflexiones sobre el exilio. Barcelona: Mondadori, 2005. 
Sarlo, Beatriz. Modernidad y mezcla cultural. En Buenos Aires, 1880-1930. La capital de un imperio imaginario, Horacio Vázquez Rial (Dir.). Madrid: Alianza Editorial, 1996, 183-190.

Sayad, Abdelmalek. La doble ausencia. De las ilusiones del emigrado a los padecimientos del inmigrado. Barcelona: Anthropos, 2010.

Silva Valdés, Fernán. Diario El País (Sección Artes y Letras), Montevideo, 6 de noviembre de 1922.

Simmel, Georg. Sociología. Estudios sobre formas de socialización. Madrid: Alianza, 1986.

Van Damme, Stéphane. "La sociabilité intellectuelle. Les usages historiographiques d'une notion”, Hypothèses, 1 (1997): 121-132.

Vásquez, Karina. "De la modernidad y sus mapas. Revista de Occidente y la 'nueva generación' en la Argentina de los años veinte”. Revista Intellectus, Vol. II (2003): 1-32 (www.2.uerj.br/intellectus).

Para citar este artículo: Rubio Hernández, Alfonso. "La calle, el café y el prostíbulo. Espacios de Sociabiliad en la obra de Pedro Herreros (1890108 1937), un poeta español emigrante en Buenos Aires”, Historia Caribe Vol. XI No. 28 (Enero-Junio 2016): 77-108. DOI: http:/ / dx.doi.org/10.15648/ hc.28.2016.4 